\title{
Fratura de órbita por queda de cavalo e correção de estrabismo
}

\section{Orbit fracture by horse fall and strabismus correction}

Abelardo de Souza Couto Junior ${ }^{1}$, Daniel Almeida de Oliveira², Clarissa Campolina de Sá Mattosinho ${ }^{3}$, Renato Curi

\section{Resumo}

Descreve-se uma paciente com fratura orbitária grave causada por queda de cavalo. Relato do seu tratamento cirúrgico com correção do estrabismo e tentativa de correção da enoftamia.

Descritores: Fraturas orbitárias; Enoftalmia/cirurgia; Transtornos da motilidade ocular; Estrabismo/cirurgia; Diplopia; Relatos de casos

\footnotetext{
${ }^{1}$ Doutor, Professor Titular de Oftalmologia da Faculdade de Medicina de Valença; Coordenador da Residência Médica em Oftalmologia do Instituto Benjamin Constant - IBC; Professor da Pós-graduação em Oftalmologia da Pontifícia Universidade Católica PUC $\mathrm{RIO} / \mathrm{SBO}$ - Rio de Janeiro (RJ), Brasil;

${ }^{2}$ Residente em Oftalmologia do Instituto Benjamin Constant - Rio de Janeiro (RJ), Brasil;

${ }^{3}$ Médica Oftalmologista com subespecialização em Glaucoma do Centro de Diagnose Ocular Copacabana - Rio de Janeiro (RJ), Brasil;

${ }^{4}$ Professor Titular de Oftalmologia da Universidade Federal Fluminense - UFF - Niterói (RJ), Brasil.

Trabalho realizado no Hospital Souza Aguiar - Rio de Janeiro (RJ), Brasil.

Recebido para publicação em: 8/9/2009 - Aceito para publicação em 27/11/2009
} 


\section{INTRODUÇÃO}

$\mathbf{O}$ $\mathrm{s}$ traumatismos de face são frequentemente acompanhados de fratura de órbita ${ }^{(1-5)}$.

Esse tipo de fratura é chamada de verdadeira quando não afeta o rebordo orbitário, como por exemplo, na fratura tipo "blow out", em que a porção posteromedial é a mais acometida por sua fragilidade. A lâmina papirácea do osso etmóide constitui outro local frágil onde frequentemente ocorre fratura ${ }^{(1,6)}$.

Várias teorias foram aventadas para a explicação do mecanismo de fratura, como transmissão de energia do bulbo ocular para a parede óssea e transmissão intraóssea, mas nenhuma isoladamente explica de maneira satisfatória todos os $\operatorname{casos}^{(3)}$. A estética e a diplopia são aspectos perturbadores para os pacientes vítimas de fratura de órbita ${ }^{(1-2,4-6)}$.

Neste relato, descreve-se um caso grave de fratura de órbita decorrente de traumatismo por queda do cavalo com seqüela de enoftalmia e diplopia, e o tratamento proposto.

\section{Relato do caso:}

Paciente do sexo feminino, 24 anos, solteira, procurou atendimento no Hospital Municipal da Piedade após traumatismo facial decorrente de queda de cavalo. Tendo sido avaliada pelo setor de Neurologia, foi encaminhada após trinta dias para o Setor de Órbita do Serviço de Oftalmologia.

Apresentava posição viciosa da cabeça, com inclinação para direita, enoftalmia, hiposfagma subtotal e midríase média de olho direito.

A acuidade visual sem correção era de 1,0 em ambos os olhos.

O reflexo fotomotor direto apresentava-se diminuído no olho direito, enquanto o reflexo fotomotor consensual apresentava-se normal.

A motilidade extrínseca estava diminuída na supraversão do olho direito, havendo diplopia bilateral quando o paciente dirigia o olhar superiormente e lateralmente à direita. No teste de cobertura, foi observada hipertropia esquerda.

À biomicroscopia, observava-se hiposfagma subtotal e midríase no olho direito. A tonometria de aplanação indicava $12 \mathrm{mmHg}$ no olho direito e 14 no esquerdo.

O teste de dução forçada apresentava moderada restrição à elevação.

A oftalmoscopia binocular indireta não demonstrava alteração em nenhum dos olhos.

O teste da pilocarpina a $0,5 \%$ foi positivo, indicando provável lesão das fibras parassimpáticas do III nervo ao nível do oblíquo inferior. A tomografia computadorizada em cortes axial e coronal ${ }^{(7)}$ apresentava fratura na parede medial, na lâmina papirácea, na parede lateral e no assoalho orbitário direito (figura 1).

A campimetria visual manual não mostrava alterações.

A exoftalmometria de Hertel era $16,5 \mathrm{~mm}$ para o olho direito e $20 \mathrm{~mm}$ para o esquerdo.

Levando-se em consideração o reflexo corneal, havia um desnível de aproximadamente $2 \mathrm{~mm}$ entre os olhos $^{(8)}$.

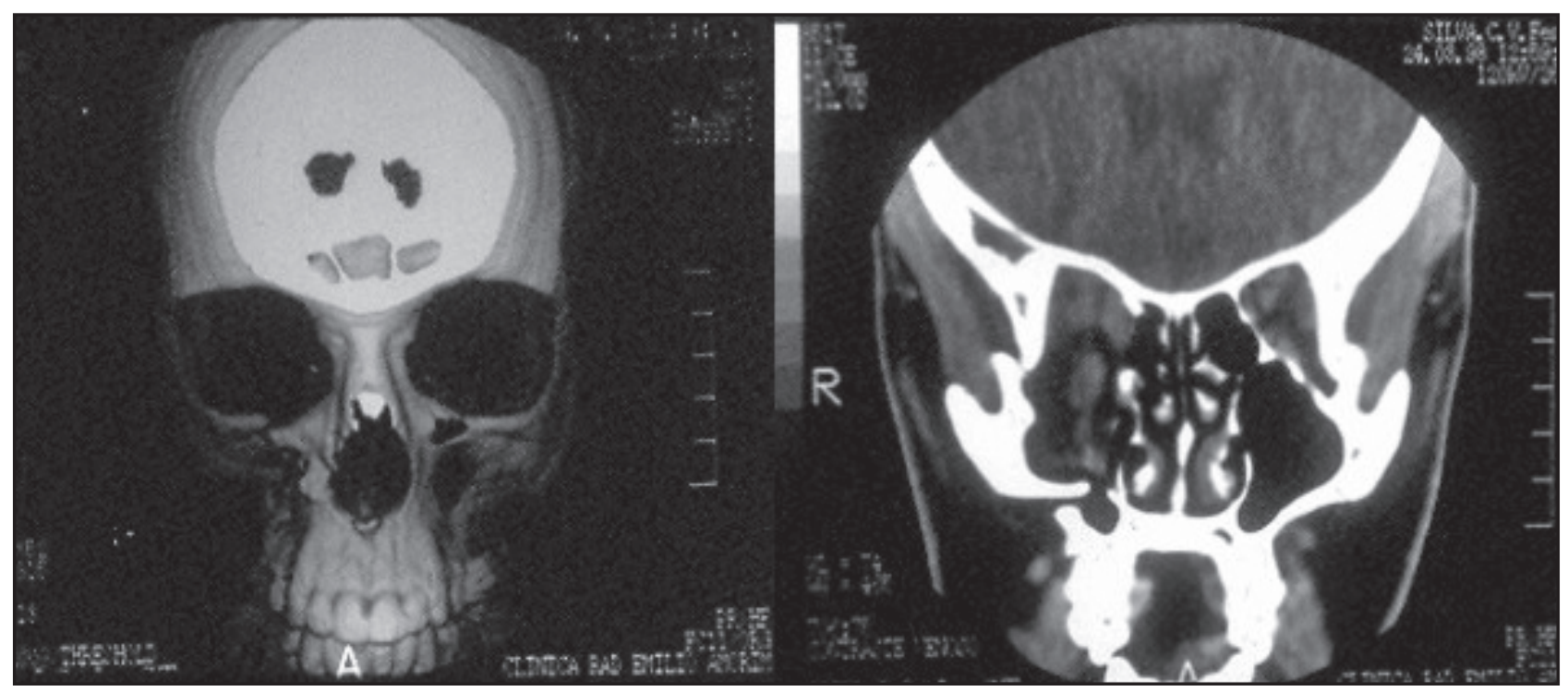

Figura 1: Tomografia computadorizada, evidenciando fratura na parede medial, na lâmina papirácea, na parede lateral e no assoalho orbitário direito 
Desse modo, foi indicada e realizada a osteossíntese do rebordo orbitário inferior com fio de aço e redução da hérnia na fratura "blow-out" com implante de polietileno poroso tipo "b sheet". Durante a cirurgia, foi necessária a colocação de duplo implante: polietileno poroso (1 $\mathrm{mm}$ de espessura) e silicone em folha (1 mm de espessura), pois o desnível entre os olhos era de aproximadamente de $2 \mathrm{~mm}^{(1-2,4-6)}$.

Nas consultas pós-operatórias foi observado alinhamento dos reflexos corneais e desaparecimento da posição viciosa de cabeça, além da enoftalmia (figura 2).

A diplopia persistia, apesar de ter sido relatada melhora subjetiva pela paciente. Optou-se por tratamento cirúrgico do estrabismo. Contudo não houve aceitação do tratamento proposto pela paciente.

Cinco meses após a cirurgia, a paciente relatou piora subjetiva da diplopia. Sete meses após a cirurgia, notou-se hipertropia esquerda. Foi constatada paresia do músculo oblíquo superior esquerdo com hiperfunção do oblíquo inferior esquerdo. O teste de Bielschowsky foi positivo para a esquerda (figura 3). A correção estrabológica constou de debilitamento do músculo oblíquo inferior esquerdo (contralateral à fratura), que resultou em recuperação total e a paciente passou a apresentar visão binocular normal ${ }^{(9)}$.

\section{Discussão}

Em relação à fratura de órbita, foi possível realizar a osteossíntese e correção do afundamento ósseo do assoalho da órbita, além do desencarceramento do reto inferior. Houve melhora significativa da diplopia e consequentemente da posição da cabeça, entretanto, ainda insuficiente para uma perfeita visão binocular. Esta somente foi obtida após debilitamento cirúrgico do músculo oblíquo inferior contralateral ao da fratura ${ }^{(1-2,6,10)}$.

A hipótese de paresia IV nervo intracraniano deve ser considerada para este caso. O IV nervo emerge na face posterior da ponte, contornando-a no véu medular anterior para se dirigir ao outro lado, onde vai inervar o oblíquo superior contralateral. No véu medular, cruza com o IV nervo oposto, que segue trajeto inverso. $\mathrm{O}$ traumatismo craniano fechado, ao mover as estruturas internas do crânio, pode provocar lesão do IV nervo, neste local de cruzamento, que pode ser uni ou bilateral. No caso em pauta, teria sido afetado o IV nervo ipsolateral à fratura orbitária, o IV nervo direito, com paresia do oblíquo superior esquerdo. Deve-se observar que a paresia do oblíquo foi no lado contrário ao da fratura orbitária, o que poderia gerar dúvida etiológica em um

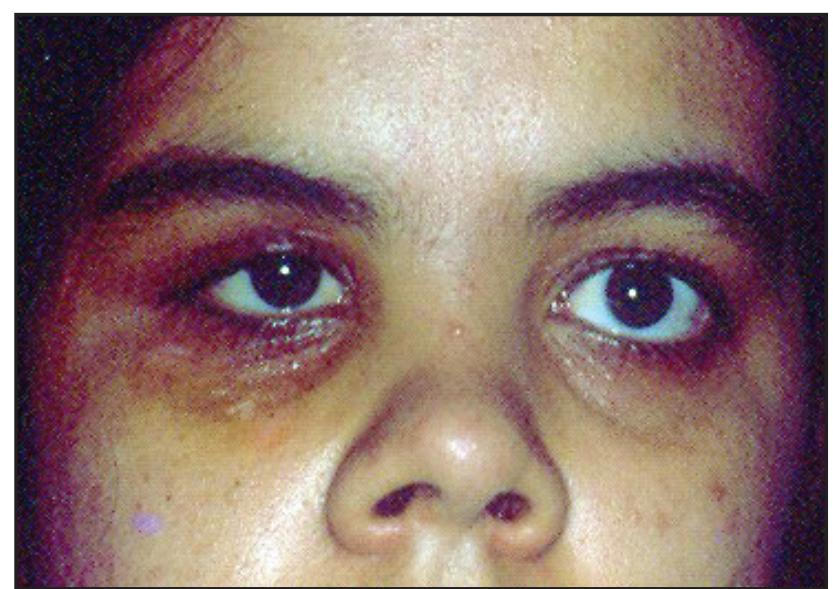

Figura 2: Situação pós-operatória: alinhamento dos reflexos corneais e enoftalmo

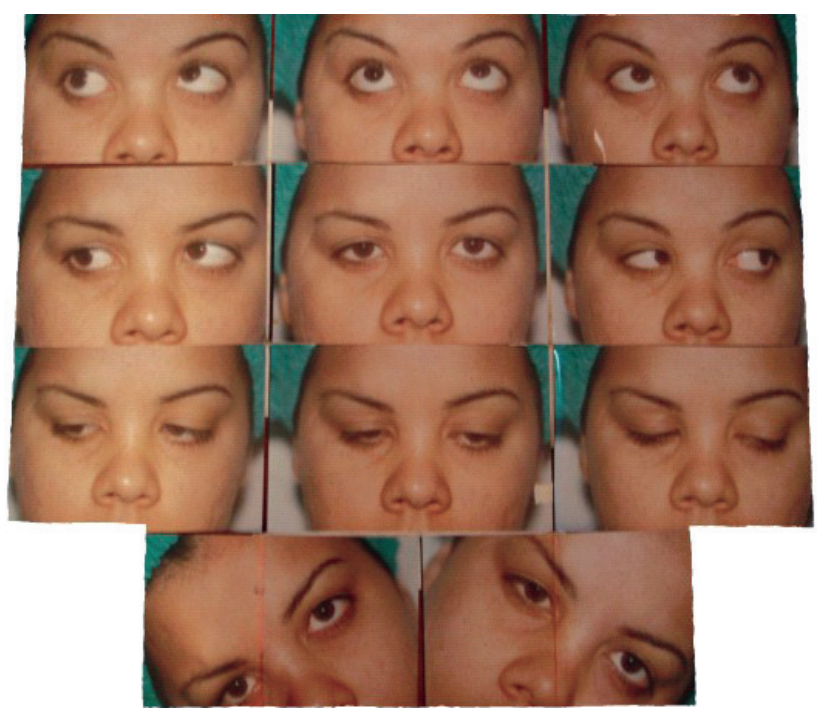

Figura 3: Posições diagnósticas, indicando paresia do músculo oblíquo superior esquerdo com hiperfunção do oblíquo inferior esquerdo

exame mais apressado ${ }^{(9)}$.

Em relação à enoftalmia, houve pequena melhora, pois a correção cirúrgica somente foi realizada quarenta dias após o traumatismo, porque a avaliação neurológica retardou a oftalmológica. Em traumas que afetem a região ocular, é importantíssima a participação conjunta do oftalmologista desde a primeira avaliação com o neurologista. Sabe-se que fraturas com mais de 2 a 3 semanas determinam uma fibrose retrobulbar difícil de ser corrigida sem iatrogenia ${ }^{(6)}$. Nesta paciente, o "foward traction test" ${ }^{(8)}$, realizado no ato operatório, foi negativo, comprovando essa assertiva. Para melhora do aspecto estético devido à enoftalmia, que muito incomodava a paciente, foi proposto um enxerto autógeno de gordura no sulco palpebral inferior ${ }^{(4)}$. 
É primordial uma avaliação multidisciplinar adequada e indicação precoce da correção cirúrgica ${ }^{(6)}$ no intuito de melhorar a qualidade de vida do paciente, com preservação da visão e da estética, reintegrando-o à sociedade. Neste caso em particular, apesar do grande esforço da equipe médica para atingir visão binocular e o melhor aspecto estético possível, a correção da enoftalmia não foi totalmente alcançada, sendo uma queixa tardia da paciente.

\section{Abstract}

Description of a patient with orbital fracture cause by a horse fall. Follow-up the surgical treatment of the strabismus and the enophtlamos.

Keywords: Orbital fractures; Enophthalmos/ surgery; Ocular motility disorders; Strabismus/surgery; Diplopia; Case reports

\section{REFERÊNCIAS}

1. Kummoona R. Management of injuries of the orbital skeleton. J Craniofac Surg. 2009;20(3):762-7.

2. Kontio R, Lindqvist C. Management of orbital fractures. Oral Maxillofac Surg Clin North Am. 2009; 21(2):209-20, vi.
3. Adeyemo WL, Aribaba OT, Ladehinde AL, Ogunlewe MO. Mechanisms of orbital blowout fracture: a critical review of the literature. Niger Postgrad Med J. 2008; 15(4):251-4.

4. Portelinha WM, Couto Jr. A, Moura EM, Zenha JC, França VP, Gonçalves JO. Fraturas orbitárias. In: Soares EJ, Moura EM, Gonçalves JO. Cirurgia plástica ocular. São Paulo: Roca; 1997. p. 426-46.

5. Couto Junior AS, Moura EM. Fratura "blow-out" da órbita. In: Freitas JA, Cardoso LM. Trauma ocular. Rio de Janeiro: Revinter; 2004.

6. Simon GJ, Syed HM, McCann JD, Goldberg RA. Early versus late repair of orbital blowout fractures. Ophthalmic Surg Lasers Imaging. 2009; 40(2):141-8.

7. Kubal WS. Imaging of orbital trauma. Radiographics. 2008; 28(6):1729-39.

8. Lahbabi M, Lockhart R, Fleuridas G, Chikhani L, Bertrand JC, Guilbert F. [Post-traumatic enophthalmos. Physiopathologic considerations and current therapeutics]. Rev Stomatol Chir Maxillofac. 1999; 100(4):165-74. French.

9. Souza-Dias C. Estrabismo. Rio de Janeiro: Cultura Médica; 1999.

10. Biesman BS, Hornblass A, Lisman R, Kazlas M. Diplopia after surgical repair of orbital floor fractures. Ophthal Plast Reconstr Surg. 1996;12(1):9-16.

\section{Endereço para correspondência:}

Abelardo de Souza Couto Jr.

Av. N. Sra. de Copacabana, $n^{\circ}$ 1120/901

CEP 22060-000 - Niterói (RJ), Brasil

e-mail: soluc@ig.com.br 